\title{
O MEMORIAL DE FORMAÇÃO COMO ESTRATÉGIA DE ENSINO E PESQUISA
}

\author{
Ladislau Ribeiro do Nascimento ${ }^{1}$
}

The autobiographical essay as a strategy for teaching and research

\section{INTRODUÇÃO}

Este artigo é fruto de uma experiência de ensino e pesquisa desenvolvida com estudantes do $9^{\circ}$ período do curso de Psicologia de uma instituição de ensino superior (IES) particular, situada em São Paulo, capital. O trabalho foi realizado por meio de oficinas, no domínio de uma disciplina denominada Gestão de Pessoas e Empreendedorismo.

Durante a programação, os estudantes preencheram questionários para avaliação do "perfil empreendedor" (DOLABELA, 1999), assistiram a vídeos sobre iniciativas empreendedoras em diferentes áreas de atuação e produziram relatos autobiográficos expressos nos respectivos memoriais. Este último recurso - o memorial de formação - é o objeto em destaque no presente texto. Ele foi pensado como estratégia de incentivo ao conhecimento de si e à reflexão sobre o próprio processo de formação. Por que seria importante lançar mão do uso de memoriais como recurso de ensino e pesquisa?

O memorial se mostra relevante porque sua produção estimula recordações e implica o sujeito-autor em rememorações capazes de ressignificar experiências e de produzir sentidos para a prática profissional baseada na ética do "cuidado de si" (FOUCAULT, 2004) como condição sine qua non para o cuidado do outro.

Esse recurso de ensino e de pesquisa tem sido utilizado em cursos de formação nas áreas de Saúde e de Educação (PASSEGI, 2006; BUOGO; CASTRO, 2013). Em alguns casos, ele é exigido como requisito parcial para obtenção de diploma em Pedagogia (SARTORI, 2008). Na área da Saúde, todavia, seu uso ainda é muito tímido. Em ambos os casos, considera-se sua relevância enquanto meio para levar os estudantes a momentos de reflexão sobre o próprio desenvolvimento, a partir da recordação seguida pela produção de narrativas sobre eventos, momentos, sentimentos,

\footnotetext{
${ }^{1}$ Doutor em Psicologia Social pela Universidade de São Paulo (USP). Professor Adjunto no Curso de Psicologia da Universidade Federal do Tocantins (UFT). Campus Universitário Miracema. Tocantins, Brasil. E-mail: ladislaunascimento@uft.edu.br
} 
escolhas e experiências situados nos mais diferentes tempos e espaços da vida de cada um dos narradores. Nas palavras de Abrahão (2011), o memorial é definido como

[...] um processo e a resultante da rememoração com reflexão sobre fatos relatados, oralmente e/ou por escrito, mediante uma narrativa de vida, cuja trama (enredo) faça sentido para o sujeito da narração, com a intenção, desde que haja sempre uma intencionalidade, de clarificar e ressignificar aspectos, dimensões e momentos da própria formação (ABRAHÃO, 2011, p. 166).

Trata-se de um método de ensino por meio do qual se desenvolvem atitudes, competências e habilidades como respeito ao próximo, capacidade de escuta e sensibilidade. Simultaneamente, opera como método de pesquisa potente para a construção de conhecimento a partir de dados autobiográficos capazes de proporcionar "[...] um conjunto alargado de elementos formadores, normalmente negligenciados pelas abordagens clássicas, e que possibilita que cada indivíduo compreenda a forma como se apropriou destes elementos formadores" (NÓVOA; FINGER, 2010, p. 24).

A relevância do memorial enquanto dispositivo de ensino, pesquisa e formação vem sendo comprovada por meio de experiências realizadas em diferentes contextos educacionais. Buogo e Castro (2013) mencionaram um projeto em que estudantes de um curso de Enfermagem elaboraram o memorial de formação como trabalho de conclusão de curso (TCC). Tendo em vista a premissa de que o cuidado do outro decorre do cuidado de si, o método autobiográfico mostrou-se potente ao viabilizar reflexões sobre “[...] aprendizagens teóricas, práticas e de identidade profissional trabalhadas no decorrer do curso" (BUOGO; CASTRO, 2013, p. 436). Segundo as autoras, este enfoque se mostra muito produtivo em termos de desenvolvimento humano e profissional.

Bergamaschi e Almeida (2013) analisaram memoriais de quatorze estudantes de Pedagogia integrados em um programa de iniciação à docência. Elas identificaram predominância de temas associados à infância e à família. Observaram aquilo que ficou entendido como "entrecruzamento de valores", percebido pelos participantes da pesquisa como legado deixado pelas respectivas famílias. Dentre os valores indicados nos relatos analisados, destaca-se o apreço pelo trabalho e pela preservação da família. Segundo as autoras, os resultados das análises sobre os memoriais fortaleceram os argumentos em favor da utilização de pesquisas autobiográficas em processos de formação, uma vez que elas viabilizam o resgate de valores como respeito, autoconfiança, honestidade e empatia, fundamentais ao exercício da cidadania e à oferta de serviços destinados ao cuidado do outro. 
Em Rosa e Baraldi (2015), professores formados em Matemática, inseridos em um curso de aprimoramento, produziram memoriais a partir do que elas chamaram de "frases disparadoras" sobre vivências no processo educacional, desde a infância, passando pela adolescência até chegar à vida adulta. Além disso, eles narraram momentos relacionados à graduação em Matemática, definida como ciência e profissão. Mencionaram a realização de cursos de formação continuada e a participação em eventos científicos, dentre outras atividades relevantes ao desenvolvimento acadêmico. Mais uma vez, os resultados demonstraram o potencial do memorial para a prática da reflexão, bem como para a criação e a ressignificação de experiências.

Oliveira (2011) mencionou uma pesquisa, no âmbito da formação de professores, em que docentes matriculados em um curso de especialização à distância produziram autobiografias e as compartilharam no ambiente virtual de aprendizagem (AVA) ${ }^{2}$. A estratégia teve o objetivo de criar alternativas ao desenvolvimento ativo dos participantes, que puderam atribuir significados ao curso e à prática docente. A partir dessa experiência, a referida autora analisou um total de 149 narrativas e constatou relatos carregados de lembranças sobre a atuação de professores que teriam marcado expressivamente a vida de muitos narradores, tanto do ponto de vista positivo quanto do ponto de vista negativo. Segundo Oliveira (2011), em virtude da dimensão reflexiva do memorial, muitos repensaram a própria identidade profissional. Assim, a força deste recurso de ensino e pesquisa e o seu potencial autoformativo foram reafirmados em um processo de ensino-aprendizagem sustentado de modo ético.

O memorial desponta como dispositivo educacional pautado em uma perspectiva ética e emancipatória, porque “[...] é pelo desenvolvimento de um saber sobre as próprias qualidades e competências que se pode tornar-se sujeito de sua formação" (JOSSO, 2010, p. 78).

O potencial de ação associado à produção autobiográfica também decorre da memória enquanto elemento fundamental para a elaboração de narrativas carregadas de “[...] 'escritas do eu', em planos históricos ricos de significados, instigados pela rememoração" (ABRAHÃO, 2011, p. 154). Vale salientar que narrar é mais do que refletir sobre algo dado como fixo, supostamente vivido internamente e passível de registro,

[...] narrar é contar uma história, e narrativas podem ser analisadas como um processo de atribuição de significado que permite a um ouvinte/leitor/apreciador do texto apropriar-se desse texto, através de uma trama interpretativa, e tecer, por meio dele,

\footnotetext{
${ }^{2}$ Ambiente Virtual de Aprendizagem (AVA) é um software voltado para a elaboração, organização e apresentação de conteúdos para cursos online, das mais distintas especificidades.
} 
significados que podem ser incorporados em uma rede narrativa própria. (GARNICA, 2003, p. 36).

O objeto de uma narrativa sobre si mesmo seria o resultado da busca do narrador pela coerência e adequação externa e interna, expressa por meio de um relato sobre aquilo que ele pensa ter feito, de um modo específico, em uma determinada circunstância (BRUNER, 1987).

Vale ressalvar que "[...] lembrar não é reviver, mas refazer, reconstruir, repensar, com imagens e idéias de hoje, as experiências do passado. Esta dinâmica ocorre porque a memória não é sonho, é trabalho" (BOSI, 1994, p. 55). Além disso, a "memória filtra, reordena, dá trelas aos desejos humanos, reescreve, fantasia, trata de uma continuidade descontinuada, cravada de abismos e vagos espaços" (FERNANDES; GARNICA, 2012, p. 175).

Além de suas dimensões pedagógica e científica, o memorial surge como agente importante na elaboração e construção identitária de sujeitos. Sua produção pode levar o narrador a um trabalho de identidade capaz de provocar mudanças em termos de atitudes, crenças, valores, ações, posicionamentos e reposicionamentos nas relações “eu-outro".

Nesta perspectiva, vale ressaltar, a identidade, ou melhor, as identidades, no plural, são definidas e afirmadas por meio de atividades (CIAMPA, 2000) desenvolvidas em relações interpessoais, e pela internalização de expectativas associadas aos papéis socialmente atribuídos aos indivíduos (STRYKER, 1968; STETS; BURKE, 2000). Neste sentido, o processo de escrita sobre si mesmo, influenciado pela rememoração de vivências e de experiências adquiridas, torna-se elemento potente para a (re)construção identitária.

Tendo em vista a força desta ferramenta com potencial para emancipar sujeitos em processos educacionais, o trabalho aqui relatado almejou desenvolver competências e habilidades por meio da reflexão atrelada à produção autobiográfica, além de gerar conhecimento acerca da formação de psicólogos. O método empregado para a elaboração dos memoriais e as estratégias utilizadas para a análise do material produzido pelos participantes estão presentes na próxima seção.

\section{Método}

O trabalho foi desenvolvido no primeiro trimestre letivo de 2016. Conforme exposto na Introdução, a produção dos memoriais foi uma dentre outras atividades propostas ao longo das oficinas vinculadas à disciplina Gestão de Pessoas e Empreendedorismo. Depois de participarem de aulas destinadas à avaliação do próprio "perfil empreendedor” (DOLABELA, 1999) e conhecerem histórias de empreendedores em diversas áreas, os estudantes receberam orientações para preparação dos memoriais. Nesta perspectiva, cada universitário deveria produzir uma narrativa 
descritiva, analítica e reflexiva sobre a trajetória percorrida desde a infância até a entrada e o percurso na formação em Psicologia.

O docente disponibilizou um roteiro para a elaboração dos memoriais e desempenhou papel de facilitador durante todo o processo (vide quadro n. 1). Vale mencionar que a estrutura dos trabalhos poderia ser modificada em função do estilo de cada um para escrever.

As oficinas para a produção dos relatos autobiográficos incluíram discussões sobre a construção da identidade profissional na contemporaneidade, além da criação de espaços para exposições e comentários sobre o processo de realização da atividade.

\section{Sobre a leitura e a análise dos memoriais}

A análise dos memoriais foi baseada no método de Análise de Conteúdo (AC) (BARDIN, 1994; BRYMAN, 2004). O processo analítico ocorreu em três fases. A primeira foi destinada para a coleta e organização dos textos autobiográficos. Em seguida, realizou-se a descrição analítica, por meio da elaboração de códigos e categorias baseados nas informações recorrentes no material lido. Finalmente, produziu-se um conjunto articulado de análises, amparado no quadro teórico utilizado para definir o memorial como recurso de formação com potencial para fomentar, por meio de reflexões e apreciações sobre a própria trajetória, o conhecimento de si.

\section{Resultados e discussão}

Produziu-se um total de 53 memoriais. Em um primeiro momento, a descrição analítica foi orientada pelos seguintes indicadores: (1) expectativas profissionais; (2) opiniões acerca da formação; (3) sentimentos produzidos no processo de formação; (4) formas de participação e de engajamento durante o curso; (5) estágio remunerado e inserção no mercado de trabalho. No entanto, a partir das leituras realizadas, os conteúdos emergentes das produções apontaram para a necessidade de criação de outras rotulações e de novos indicadores, conforme exposto a seguir: (1) lembranças sobre a infância e a adolescência; (2) decisão pela graduação em Psicologia; (3) situações marcantes ao longo do curso; (4) a experiência de escrever acerca de si mesmo.

\section{LEMBRANÇAS SOBRE A INFÂNCIA E A ADOLESCÊNCIA}

Destacamos episódios em que, ante a pluralidade das lembranças narradas, evidenciam-se as que foram marcantes e significativas ao longo da trajetória. Apresentamos, inicialmente, fragmento sobre situações positivas, vivenciadas com alegria e entusiasmo.

Que infância feliz! Vivi numa casa a 100 metros da praia, onde nadava, pescava siri e brincava no mar em boias grandes de pneus... Em casa tinha muitas árvores: três 
goiabeiras, três mangueiras, e um enorme abacateiro de onde se enxergava o bairro vizinho de tão alto que era. Nunca vi nada igual! (memorial 52/53)

Constatou-se, todavia, haver também lembranças sobre momentos de tristeza e de conflito:

[...] Tive uma adolescência marcada pela falta da minha mãe. Nunca tivemos muito diálogo e o clima em casa era de tensão, pois minha mãe tinha, muitas vezes, reações extremas com gritos e cobranças por limpeza e ordem (memorial 4/53).

Os dois fragmentos oferecem pistas sobre a característica plural dos relatos em que as experiências significativas foram apontadas. Histórias envolvendo ganhos e perdas em diferentes fases da vida foram narradas de modo singular. Além do que se observou nos trechos expostos, compuseram os memoriais outras vivências acumuladas pelos participantes ao longo dos anos, tais como: chegada de novos membros à família, divórcio dos pais e até mesmo situações extremas como o falecimento de entes queridos em acidentes. A exemplo do que foi constatado por Bergamaschi e Almeida (2013), as narrativas mostraram presença marcante de experiências e vivências associadas à infância e à família.

Relatos e lembranças sobre o processo de formação educacional básica ocuparam bastante espaço nos textos. Os narradores contaram histórias sobre experiências no cotidiano escolar. Uns recordaram importantes figuras de referência, tais como professores e amigos dos tempos de ensino fundamental e médio. Outros, por sua vez, relataram dificuldades e desafios enfrentados, incluindo problemas como: depressão, desligamento do colégio após a prática de atos de indisciplina e sofrimento derivado de rejeição na relação com os colegas de turma.

\section{DECISÃO PELA GRADUAÇÃO EM PSICOLOGIA}

Esta seção expõe algumas justificativas para a decisão de cursar Psicologia e destaca experiências marcantes durante o período cursado até o momento da escrita do memorial. Os relatos indicaram predominância de estudantes que disseram ter escolhido a formação em Psicologia em virtude do desejo de contribuir de algum modo para melhorar a vida de outras pessoas.

[...] depois de um ano só trabalhando, queria fazer algo que me proporcionasse ser útil para a sociedade, então quis cursar psicologia [...] (memorial 01/53).

Queria ajudar o próximo. Isso não me saía da cabeça nem da vontade (memorial 53/53).

Houve quem associasse a escolha pela Psicologia ao contato com alguma figura de referência: 
[...] fui influenciada pelo meu professor de Filosofia do colégio. Ele falava muito sobre Freud e eu passei a me interessar pela Psicologia (memorial 06/53).

[...] fiz terapia porque sofria muito devido a minha timidez. Eu percebi como a Psicologia era importante. Foi muito bom pra mim. Daí escolhi ser psicóloga para ajudar outras pessoas (memorial 18/53).

Alguns relatos indicam a decisão pelo curso depois da inserção em outras áreas de conhecimento e de atuação profissional.

Em 2007 ingressei na faculdade de Letras - Português/Inglês simplesmente porque queria ter uma formação superior e como gostava muito da língua portuguesa decidi me inserir nesse meio para me aprimorar e trabalhar com revisão de textos e também foi o curso que eu tinha condições financeiras em arcar, mas a psicologia já estava na minha mente (memorial 52/53).

Trabalhei no campo do Direito. Desde o início, sentia que não estava no lugar certo, não conseguia me visualizar desenvolvendo essa atividade em minha vida. Mas queria muito trabalhar, ganhar meu dinheiro. E segui com esse conflito. O tempo foi passando [...]. Comecei a adoecer, não conseguia sair e nem escolher um novo rumo para minha vida. Foi quando meu marido teve a ideia de estudar por um ano fora do país [...] Lá aprendi a falar francês e fiz cursos de mediação de conflitos e arteterapia. Ao voltar ao Brasil, conversando com meu marido, mencionei a vontade de estudar psicologia (memorial 04/53).

Em relação ao fragmento anterior, observa-se uma sequência de fatos: formação em Direito, dúvida em relação à decisão pela área, conflito, cursos de mediação de conflitos e arteterapia, retorno ao Brasil, declaração sobre a "vontade de estudar psicologia". Is so nos remete àquilo que Fernandes e Garnica (2012) definem como a capacidade da memória para filtrar, reordenar e tratar de uma "continuidade descontinuada". Afinal, as experiências vividas não seguem uma lógica linear; há espaçamentos, inflexões, avanços, retrocessos, dúvida e medo, dentre outros movimentos. Todavia, conforme podemos inferir a partir da leitura do fragmento anterior, a despeito da referida descontinuidade da vida, a possibilidade de rememoração acompanhada de reflexão (ABRAHÃO, 2011) permitiu clarificação e ressignificação de aspectos, dimensões e momentos vividos.

\section{SITUAÇÕES MARCANTES AO LONGO DO CURSO}

Os relatos dão indícios de que as trajetórias de formação se constituem através de acontecimentos e de experiências capazes de produzir marcas importantes na constituição de cada 
sujeito. Muitos mencionaram dificuldades enfrentadas durante os períodos letivos cursados, em função dos limites de tempo e do desgaste físico, relacionados ao exercício de alguma prática laboral em paralelo à formação em Psicologia. Em contrapartida, outros versaram sobre a oportunidade de investir na realização de cursos extracurriculares, dentre outras atividades necessárias para a qualificação acadêmica e profissional.

Nos dois próximos excertos, ressaltamos a operação da memória entendida como trabalho (BOSI, 1994). Notamos a rememoração de experiências do passado sob a influência de imagens e ideias do presente. Constatamos, na mesma perspectiva, o (re)conhecimento de qualidades e competências necessárias ao desenvolvimento acadêmico e profissional (JOSSO, 2010).

Neste momento, pensando nesta fase vivida, consigo voltar no tempo e me ver indo para o colégio todos os dias ao lado dos meus pais [...]. Finalmente estaria realizando o meu grande sonho de estudar. Não sabia o que isto significava, mas queria muito ir para a escola [...] O nome da minha professora era Margarida ${ }^{3}$. Lembro-me do quão queria ser igual a ela quando crescesse. [...] Hoje estou no quinto ano de Psicologia e me sinto no meu lugar, onde eu realmente deveria estar. A graduação em Psicologia me fez amadurecer muito, me fez enxergar o mundo de outra maneira. Ganhei uma visão analítica de tudo [...]. Acredito que foi uma das melhores escolhas. Tive muitos professores de referência. Eles me influenciaram nas áreas escolhidas e quem sabe um dia eu possa escolher alunos para a minha monitoria e mudar a vida deles também, como a professora Orquídea ${ }^{4}$ me mudou (memorial 2/53).

Quando estava cursando o quinto semestre começou a disciplina sobre psicopatologia, não sei se foi a maneira com a qual a professora nos apresentou os transtornos mentais, mas me interessei de uma tal maneira por essa área que descobri que era exatamente por isso que eu entrei na psicologia, para trabalhar com casos graves, problemas reais, questões que realmente atrapalhavam a vida de um indivíduo e de sua família. Durante boa parte da minha vida me vi como uma pessoa fria, que não gostava ou não tinha jeito com crianças. Porém, na escola [local onde a narradora realizou estágio de formação], tive contato com meu lado criança e percebi que a Psicologia do Desenvolvimento e Escolar é uma das áreas que me toca, que me ensina e que faz eu encontrar o sentido que procuro em tudo que faço (memorial 51/53).

Além do que se pôs em destaque nesta seção, os narradores versaram sobre a importância de se desenvolver e manter uma rede de apoio para o enfrentamento dos inúmeros desafios na

\footnotetext{
${ }^{3}$ Nome fictício.

${ }^{4}$ Idem.
} 
graduação. Vale salientar que o público-alvo da IES onde esta atividade foi realizada é composto majoritariamente de pessoas oriundas da classe trabalhadora. Conforme indicado, a maioria estava inserida no mundo do trabalho e conciliou atividades laborais e acadêmicas.

\section{SOBRE A EXPERIÊNCIA DE ESCREVER ACERCA DE SI MESMO}

Conforme apontado extensivamente neste trabalho, a composição do memorial vai além da descrição de fatos ocorridos na trajetória percorrida. O exercício da escrita sobre si mesmo cria espaços para a atribuição de significados acerca da própria história de vida e viabiliza a (re)interpretação de experiências (GARNICA, 2003).

Escrever este memorial foi muito gratificante, pois caminhei em busca do meu passado adormecido [...]. Elaborar esse texto foi um desafio que me convidou a desconsiderar as trajetórias lineares da minha vida [...]. Novos caminhos, dificuldades, descobertas e redescobertas fizeram-me perceber que o tempo todo eu pude me reinventar. Eu só não tinha consciência disso. Entendi que a minha formação, como a de qualquer outra pessoa, deve ser pensada considerando as descontinuidades da existência (idade, mudanças, perdas, descobertas) [...] Foi nesse jardim de flores, espinhos e muros que me tornei parte do mundo e deixei a escola, a pedagogia, o vinho $^{5}$ e a Psicologia se tornarem parte do que fui, do que sou e do que serei (memorial 3/53).

Agradeço pela oportunidade que você nos proporcionou em podermos parar e ver a nossa evolução profissional através de uma produção textual (memorial 7/53).

Mais uma vez, o memorial promoveu conhecimento de si por meio de reflexões e análises sobre história de vida. Por meio dele foram acessadas áreas que, pelas estratégias tradicionais de ensino e aprendizagem, são inatingíveis (NÓVOA; FINGER, 2010).

Este dispositivo oferece elementos formativos condizentes com as demandas pela formação de psicólogos que sejam capazes de agir de modo empático, sensíveis à dor do outro, engajados na luta pelo enfrentamento de situações geradoras de sofrimento nos mais diferentes espaços de atuação.

\footnotetext{
${ }^{5} \mathrm{Na}$ versão integral do texto, a narradora cita um curso que fez de sommelier de vinhos.
} 


\section{CONSIDERAÇÕES FINAIS}

Este trabalho corroborou estudos e relatos sobre a relevância do relato autobiográfico. $\mathrm{O}$ memorial se mostrou crucial na mobilização de sujeitos para a elaboração de reflexões e análises sobre as trajetórias pessoal, acadêmica e, muitas vezes, profissional.

Sua potência enquanto dispositivo criativo, capaz de estimular a "memória-trabalho" (BOSI, 1994), coloca-o em posição de destaque entre as estratégias de ensino e de pesquisa voltadas para a emancipação e o engajamento de profissionais situados em campos de atuação em que o cuidar se faz crucial.

O memorial operou como instrumento apropriado para confrontar a lógica disciplinar predominante nos modelos clássicos de ensino (FOUCAULT, 1987). Ele despontou como ferramenta útil para situar o sujeito-autor-narrador no centro dos processos de ensinoaprendizagem. Deste modo, evidenciou-se sua eficácia para promover os desenvolvimentos acadêmico e profissional baseados no compromisso ético-político-social da Psicologia.

Novas práticas de ensino e de pesquisa envolvendo o uso deste instrumento precisam surgir para ampliar o alcance das atividades reflexivas e analíticas. Os efeitos provenientes da utilização do método autobiográfico convergem para instituir saberes e fazeres cruciais para a atuação profissional em Psicologia. Refletir sobre o próprio trajeto de formação e analisá-lo são ações vitais para quem está prestes a trabalhar como agente de transformação voltado ao (re)conhecimento e à recusa de práticas que aprisionam subjetividades e geram mal-estar. 


\section{Referências}

ABRAHÃO, M.H.M.B. O sujeito singular-plural -narrativas de trajetórias de vida, identidade profissional e saberes docentes. In: PASSEGGI, M. C.; SOUZA E. C.; Abrahão, M.H.M.B. (Orgs.), Pesquisa (auto) biográfica e práticas de formação, Rio Grande do Norte-Natal, Paulus/ EDUFERN, 2008, Vol. 1, p. 81-105.

ABRAHÃO, M. H. M. B. Memoriais de formação: a (re)significação das imagens-lembranças/recordações-referências para a pedagoga em formação. Educação, Porto Alegre, v. 34, n. 2, p. 165-172, maio 2011.

BARDIN, L. Análise de conteúdo. Lisboa: Edições Setenta, 1994, 226 p.

BERGAMASCHI, M. A.; ALMEIDA, D. B. (2013). Memoriais escolares e processos de iniciação à docência. Educação em Revista, Belo Horizonte: MG. vol. 29, n .2, 15-41. Disponível em: < https://dx.doi.org/10.1590/S0102-46982013000200002>, Acesso em 12 dez. 2017.

BOSI, E. Memória e sociedade: lembranças de velhos. 4. ed. São Paulo, Companhia das Letras, 1994, 484p.

BRUNER, J. Life as narrative. Social Research, Vol. 54, N. 1, 11-32, Spring, 1987.

BRYMAN, A. Quantity and quality in social research. London ; New York : Routledge, 2004, 198p.

BUOGO, M.; CASTRO, G. de. Memorial de formação: um dispositivo de aprendizagem reflexiva para o cuidado em saúde. Trabalho, Educação e Saúde, Rio de Janeiro, v. 11, n. 2, p. 431-449, Agosto 2013. Disponível em: < http://www.scielo.br/scielo.php?script=sci_arttext\&pid=S1981-

77462013000200010\&lng=en\&nrm=iso >. Acesso em: 10 fev. 2018.

CIAMPA, A.C. A estória do Severino e a história da Severina. São Paulo: Brasiliense, 2000, 123p.

DOLABELA, F. Oficina do empreendedor: a metodologia de ensino que ajuda a transformar conhecimento em riqueza. São Paulo: SP, Cultura Editores Associados, 1999, 275p.

FERNANDES, D. N.; GARNICA, A.V. M. Temporalidades Distintas: um estudo sobre a formação de professores de matemática no Maranhão. In: FERREIRA, A.C.F.; BRITO, A.J.; MIORIM, M.A.(Orgs). Histórias de Formação de Professores que Ensinaram Matemática no Brasil. 1 ed. Campinas: Ilion, 2012, v. 1, p. 175-189.

FOUCAULT, M. Vigiar e punir. 27ª Edição. Petrópolis: Vozes, 1987, 288p.

A ética do cuidado de si como prática da liberdade. In:

Ditos e Escritos V. Ética, Sexualidade e Política. Rio de Janeiro: Forense Universitária, 2004, p. 264-287.

GARNICA, A.V. M. História Oral e Educação Matemática: do inventário à regulação. Revista Zetetiké, Campinas, v.11, n. 19, p. 9-55, Jan.- Jun, 2003.

JOSSO, M.C. Da Formação do Sujeito... Ao Sujeito da Formação. In. NÓVOA, A.; FINGER, M. O Método (auto)biográfico e a Formação. Natal, RN: EDUFRN; São Paulo: Paulus, 2010, p. 59-79.

NÓVOA, A.; FINGER, M. O método (auto)biográfico e a formação. Natal: EDUFRN; São Paulo: Paulus, 2010.

OLIVEIRA, M. Práticas educativas e narrativas (auto) biográficas em ambientes virtuais de aprendizagem. Revista Teias, Rio de Janeiro, v. 12 n 25, p. 171- 185, maio/ago, 2011.

PASSEGGI, M. C. A formação do formador na abordagem autobiográfica: a experiência dos memoriais de formação. In: Souza, E. C., Abrahão, M. H. M. B. (Orgs.). Tempos, narrativas e ficções: a invenção de si. Porto Alegre: EDPUCRS, Salvador: EDUNEB, 2006, p. $203-218$.

ROSA, F. M. C. DA.; BARALDI, I. M. O uso de narrativas (auto)biográficas como uma possibilidade de pesquisa da prática de professores acerca da Educação (Matemática) Inclusiva. Bolema: Boletim de Educação Matemática, vol. 29, n. 53, 936-954, 2015. Disponível em: https://dx.doi.org/10.1590/1980-4415v29n53a08 Acesso em: 13/11/2017.

SARTORI, A. T. Os professores e sua escrita: o gênero discursivo "memorial de formação". (Tese de Doutorado). UNICAMP. Campinas: SP, 2008, p. 202.

Stets, J. E., \& Burke, P. J. (2000). Identity theory and social identity theory. Social Psychology Quarterly, Vol. 63, N. 3, p. 224-237, Sep. 2000. Disponível em:< http://www.jstor.org/stable/2695870 > Acesso em: 11 Nov. 2017.

Stryker, S. (1968). "Identity Salience and Role Performance". Journal of Marriage and the Family, Vol. 30, no. 4, p. 558-564, 1968. Disponível em: 〈https://www.jstor.org/stable/349494?seq=1\#page_scan_tab_contents> Acesso em: 11 Nov. 2017. 
Quadro n. 1: Roteiro para a elaboração do memorial.

\begin{tabular}{|l|}
\hline I. Dados históricos biográficos \\
- Nascimento \\
- Local de origem \\
- Vida escolar \\
- Realizações na trajetória de vida \\
\hline II. Graduação: \\
- Cursos Frequentados \\
- Iniciação Científica \\
- Eventos científicos \\
- Publicações \\
- Monitorias \\
- Estágios \\
- Extensão \\
- Especialização \\
- Pós-graduação \\
\hline III. Carreira profissional \\
- Experiência profissional \\
- Realizações na carreira \\
\hline IV- Considerações \\
\hline
\end{tabular}




\section{RESUMO}

O presente artigo parte de uma experiência em que o memorial foi pensado como estratégia de ensino e pesquisa. O trabalho contou com a participação de acadêmicos do 90 período de um curso de Psicologia ofertado em uma instituição de ensino superior (IES) privada, situada na capital do estado de São Paulo. A atividade foi projetada para estimular nos estudantes a elaboração de reflexões e análises sobre suas trajetórias pessoal, acadêmica e profissional. Produziu-se um total de 53 memoriais, posteriormente submetidos à análise de conteúdo. Os resultados indicaram o potencial deste recurso para fomentar rememorações e ressignificações de experiências vivenciadas pelos participantes em diferentes contextos.

Palavras-chave: Memorial de Formação. Ensino. Educação.

\section{ABSTRACT}

The present article emerged from the author's experience using the autobiographical essay as both a research and a teaching strategy. The study was carried out with psychology undergraduate students at a private university in São Paulo, Brazil. The autobiographical essay was designed with the aim of motivating students to analyze and reflect on their personal, academic, and professional trajectories. $A$ total of 53 autobiographical essays were produced and later submitted to content analysis. The results indicate the potential of this procedure to foster recollections and promote the resignification of experiences lived by students in different contexts.

Keywords: Autobiographical Register. Teaching. Education.

\section{EL MEMORIAL DE FORMACIÓN COMO ESTRATEGIA DE ENSEÑANZA E INVESTIGACIÓN}

\section{RESUMEN}

El presente artículo surgió de la experiencia del autor mediante el memorial de formación como una parte de investigación y una estrategia de enseñanza. El estudio se llevó a cabo con estudiantes de psicología de pregrado en una universidad privada en São Paulo, Brasil. El memorial de formación fue diseñado con el objetivo de motivar a los estudiantes a analizar y reflexionar sobre sus trayectorias personales, académicas y profesionales. Un total de 53 ensayos autobiográficos fueron producidos y luego sometidos a análisis de contenido. Los resultados indican el potencial de este procedimiento para fomentar los recuerdos y promover la resignificación de las experiencias vividas por los estudiantes en diferentes contextos.

Palabras clave: Memorial de Formación. Enseñanza. Educación. 